BIOLOGICAL SCIENCES

\title{
Main causes of bird-window collisions: a review
}

\author{
LAY G. BASILIO, DANIELE J. MORENO \& AUGUSTO J. PIRATELLI
}

\begin{abstract}
Bird-window collisions are a major cause of bird mortality in the world; up to one billion birds die each year from collisions with glass panes in North America alone. However, relatively little attention had been given to this issue in the broad scientific literature, despite a recent increase in the number of papers. In this paper, the indexed literature on bird-window collisions was reviewed, specifically addressing the causal factors. The search retrieved 53 papers, mostly from North America. The factors linked to higher collision rates were large areas of continuous glass, the presence of nearby vegetation and feeders, bird migration, abundance, and behavior. Several factors were site-specific, preventing the global extrapolation of these findings. There is a lack of scientific knowledge regarding bird-window collisions in tropical countries. One of the challenges to mitigating this problem is the small amount of information and frequently - the extrapolation of findings described for temperate regions to other areas. There is a need for a greater and urgent effort to fill this gap.
\end{abstract}

Key words: bird strikes, bird-friendly buildings, glass panes, human-made structures, urban birds.

\section{INTRODUCTION}

Human-population growth has led to the conversion of areas of natural ecosystems into anthropogenic landscapes (Foley et al. 2005), of which urban settlements are one of the most artificial; becoming increasing more so with time (McDonald 2008). They harbor numerous dangerous features to birds that result in billions of bird deaths every year (Erickson et al. 2005, Klem 2006, Santiago-Alarcon \& Delgado-V 2017).

Glass panes became widespread in urban design projects after a boom in the glass industry after World War II (Klem 1989). Following the growth of anthropogenic landscapes and manmade structures worldwide, birdwindow collisions have become more common (Klem 2009a, Bayne et al. 2012). They are now considered one of the most significant causes of bird mortality in the world (e.g. Klem 2006, 2009b). Estimates of the death rates from Canada and the United States range from 16 to 42 and 365 to 988 million birds a year, respectively (Machtans et al. 2013, Loss et al. 2014). Even still, these alarming rates may be underestimates, since not all individuals die immediately after a collision (Klem 1990a), and carcasses can be quickly removed by scavengers (Bracey et al. 2016).

The topic of bird-window collisions has been addressed in the scientific literature with early papers concentrating on species, season and causes of collisions (e.g. Klem 1989). More recent research has summarized this information (Erickson et al. 2005) to provide more practical results and liable ways of preventing collisions (Klem 2009b). Many studies have also highlighted the importance of long-term studies and monitoring (Bayne et al. 2012). Along with researchers' efforts, citizen 
science has also been incorporated into the data collection phase of these studies (Bayne et al. 2012, Kummer et al. 2016a).

This topic has only recently received more attention from researchers and policymakers (Barton et al. 2017), despite having been widely reported in the media (Erickson et al. 2005). The number of scientific studies is therefore still limited (Santiago-Alarcon \& Delgado-V 2017, but see Seewagen \& Sheppard 2018), mainly in tropical regions, where only a few local studies are known (e.g. Agudelo-Álvarez et al. 2010, Brisque et al. 2017, Santos et al. 2017). An update on existing data is required, aiming to identify collision patterns, to fill in knowledge gaps and identify the most threatening scenarios.

The main objectives of this paper are to (a) estimate how many papers have been published on indexed databases on bird-window collisions; (b) identify the geographical distribution of these publications; (c) identify the taxonomic groups most-frequently involved in collisions and; (d) understand the factors that cause birds to collide with glass panes.

\section{MATERIALS AND METHODS}

A systematic review was carried out on the Web of Science (using the Web of Knowledge searching tool), Scopus and SciELO databases, with the keywords "bird AND collision AND window"; replacing "bird" with "avian"; "collision" with "strike" or "crash"; and "window" with "glass", which resulted in 12 search combinations. No filters were added for language, and the search was completed in June 2018. As the main goal was to sample papers published in peerreviewed journals that addressed the possible causes of bird-window collisions, all texts that did not meet this criterion were excluded. Papers were analyzed to understand their temporal and geographical scope. Information was also extracted to detect patterns, organized as described below.

Specific information was collected on four topics, 1) geographical patterns of records; 2) species involved in collisions; 3 ) species richness by families; 4) features that may increase the risk of collisions both at the taxonomic (i.e., species and families) and environmental levels. To understand the geographical occurrence of records, papers that did not refer to any specific locality were excluded. Some papers cited more than one study site (e.g. city, country, continent), and all of them were included. Several factors may affect the likelihood of a collision (Hager et al. 2008), in a combination of intrinsic (taxonspecific experiences and behaviors) and extrinsic causes (e.g. adjacent vegetation and glass pane type) (Sabo et al. 2016). These different factors were arranged into four categories: speciesspecific, weather conditions, surroundings and types of construction, with complex interactions among them (Kahle et al. 2016).

\section{RESULTS}

\section{Estimates}

A total of 53 articles were retrieved, with a tendency to increase the number of publications in the last few years (Fig. 1). Most publications came from the Northern Hemisphere $(n=43$; 81.13\%), mainly the United States and Canada (Table I). Some papers $(n=5)$ had more than one study site and five were not specific to any region (revision papers). More than 90\% ( $n=49)$ of the studies were published in English but some in French, Spanish, German and Portuguese (one each) were also found. 


\section{Species and susceptibility to collisions}

A total of 304 species from 58 families were reported to have collided with glass panes (Supplementary Material Table SI). The species that collided most were White-throated Sparrow (Zonotrichia albicollis) ( $n=21$ papers), Dark-eyed Junco (Junco hyemalis) ( $n=20)$, American Robin (Turdus migratorius) ( $n=20)$ and Swainson's Thrush (Catharus ustulatus) $(n=17)$. Some species are more likely to collide than others, due to their behavior (Dunn 1993, Newton et al. 1999) and migratory status (Loss et al. 2014, Sabo et al. 2016). The effects of age and morphology are not clear (Klem 1990b, Kahle et al. 2016, Sabo et al. 2016).

\section{Weather and seasonality}

There are collisions throughout the year in the Northern Hemisphere, with an increase in spring, autumn and summer (Borden et al. 2010, Ocampo-Peñuela et al. 2016), and a reduction in the winter time (Hager et al. 2012, Bayne et al. 2012), linked with both the species behavior and the seasonal environmental changes (Hager \& Craig 2014, Kahle et al. 2016). There is no consensus on the effect of local weather conditions on collisions (e.g. Cousins et al. 2012, Hager et al. 2012, Ocampo-Peñuela et al. 2016, Brisque et al. 2017).

\section{Surroundings}

Environmental heterogeneity positively influences the abundance and diversity of birds (Hager et al. 2013). If bird abundance and diversity are correlated with more collisions (Hager et al. 2008, Kahle et al. 2016) they may be higher in these places. Thus, collisions are more frequent in rural than in urbanized areas (Kummer et al. 2016b), and the proximity of glass panes to urban green areas and artificial feeders may also catalyze such accidents (Dunn 1993, Borden et al. 2010, Kummer \& Bayne 2015).

\section{Types of construction}

Buildings with a higher relation of continuous glass pane areas were identified as having a greater risk (Cusa et al. 2015). Reflective or translucent glasses are also more dangerous (Klem \& Saenger 2013, Klem 2015, Kummer et al. 2016b).

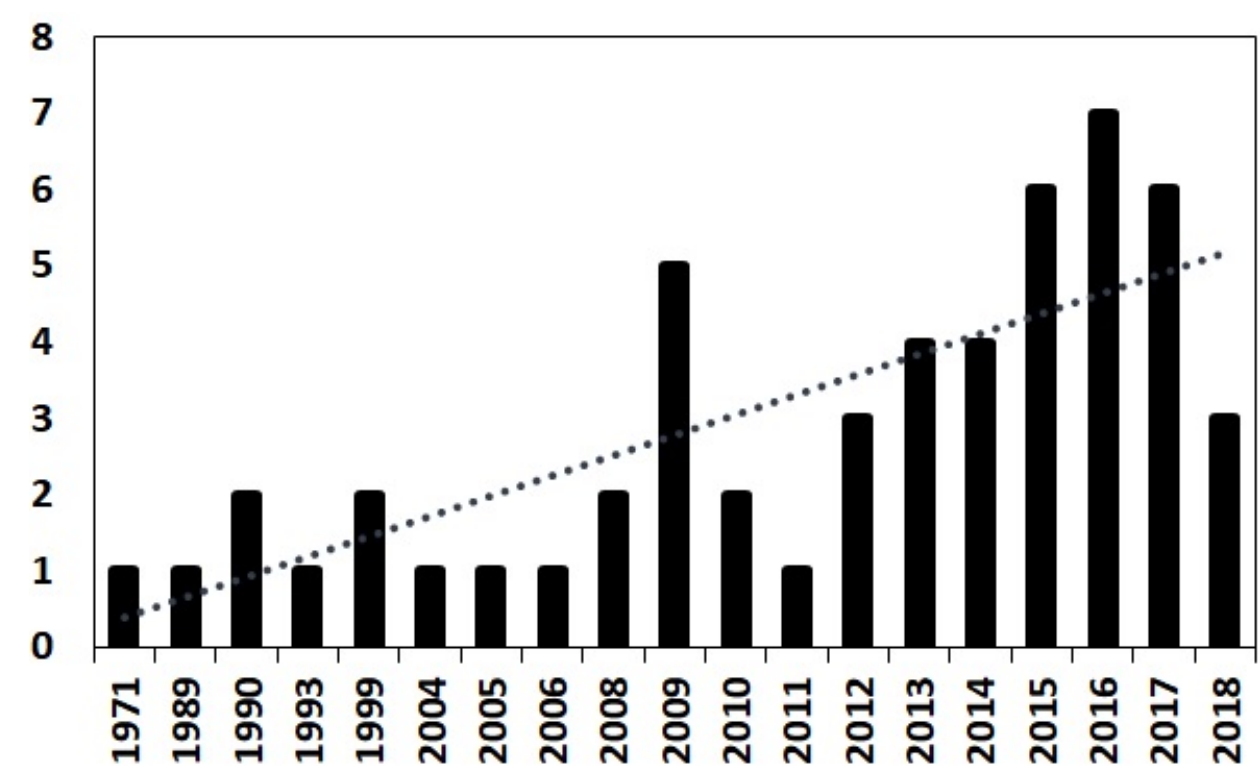

Figure 1. Number of published papers on bird-window collisions over time. 
Table I. Geographic distribution of published studies on bird-window collisions.

\begin{tabular}{|c|c|}
\hline Country/Region & Number of papers \\
\hline Austria & 1 \\
\hline Brazil & 3 \\
\hline Canada & 8 \\
\hline Colombia & 1 \\
\hline England & 1 \\
\hline Ireland & 1 \\
\hline New Zealand & 1 \\
\hline North America & 1 \\
\hline Poland & 1 \\
\hline South Korea & 1 \\
\hline Sweden & 1 \\
\hline Swiss & 1 \\
\hline USA & 23 \\
\hline USA and Canada & 4 \\
\hline Revision paper & 5 \\
\hline Total & $\mathbf{5 3}$ \\
\hline
\end{tabular}

\section{DISCUSSION}

\section{Estimates}

Most of the papers considered in this review are from the United States and Canada. Although the first research that marginally discuss this topic has a British origin (Glue 1971), North American countries are also home to early publications (e.g. Klem 1989, 1990a, b). There is a clear imbalance in the scientific production and, therefore, in the knowledge of bird-window collisions. Most studies are from the Northern Hemisphere, while information from the Southern Hemisphere is still scarce (but see Ocampo-Peñuela et al. 2016, Brisque et al. 2017, Santos et al. 2017). This is worrying because most of the world's bird species reside in tropical countries (Myers et al. 2000), and many can be decreasing partly due to collisions with human structures. Thus, the extension of the geographic coverage of studies on bird collisions may contribute to the development of local solutions since different bird communities have distinct characteristics and behavior.

Estimates of collision rates are often based on detection of carcasses, but this may be biased if the search effort is sporadic. This may result in a significant loss of information (Gelb \& Delacretaz 2009). Thus, studies on carcass longevity and detection may provide more details of this bias and should be considered in future analyses (Hager et al. 2013, Parkins et al. 2015). This is easier to check in local studies (e.g. research in a specific neighborhood) (Bracey et al. 2016). However, in large-scale surveys such as nationwide questionnaires or collaborative platforms, there is no way to correct for this bias (Kummer et al. 2016c).

The presence of scavengers and the duration that carcasses remain are sitespecific. Therefore, different localities should be considered separately. However, generally speaking, the longer the exposure, the greater the chance that a carcass may be removed by a scavenger (Bracey et al. 2016). Areas that are paved or have low vegetation cover also have longer carcass durability (Hager et al. 2012). Carcasses of smaller species also remain for shorter durations since a greater variety of scavengers may carry them off (Hager et al. 2012, Bracey et al. 2016). Scavengers may also learn where to find bird carcasses, often visiting buildings responsible for collisions (Klem et al. 2004). Solutions to overcome the biases caused by scavengers may be both more frequent rounds - aiming to collect dead birds before they are scavenged - and counting feathers, since half of all scavengers leave behind remains of a carcass (Hager et al. 2012). Some surveys look for more than just a dead bird as evidence of a window collision (e.g. window smudges or blood, seeing a bird, citizen-science and memory-recall surveys (Kummer et al. 2016a). However, local experiences (e.g. Brisque et al. 2017, Ribeiro \& 
Piratelli in press) suggest that routine searches may also fail to accurately detect collisions.

\section{Species and susceptibility to collisions}

It is important to know why some species are more prone to collisions than others in order to understand the impact of these collisions on species' populations (Loss et al. 2014), but few studies looked at this (Klem et al. 2004). The first study to investigate this aimed not only to report collisions, but also to understand the factors behind them and concluded that the collision rate is a function of population density (Klem 1989). This was later supported for collisions close to feeders where species with higher mortality rates corresponded to those with greater abundance (Dunn 1993). However, the likelihood of a collision is not only determined by the species' abundance (Kahle et al. 2016) as it varies completely independently of the relative abundance of certain species (Sabo et al. 2016). Thus, it is likely that there are more complex relationships among a variety of factors (Parkins et al. 2015). Most worrying, perhaps, are cases in which less abundant species are more likely to collide, especially if their populations are already in decline (Arnold \& Zink 2011).

Recent studies stressed the greater susceptibility of migratory species to collisions (Arnold \& Zink 2011, Sabo et al. 2016), explaining the greater fatality rate during migration (Hager et al. 2008). More than $70 \%$ of the bird species involved in collisions in the Northern Hemisphere are migratory (Loss et al. 2014, Parkins et al. 2006). These bird species may not be as familiar to the sites as the residents are (Kahle et al. 2016). Although some authors claim that the darkness of night increases the chances of collisions (Ogden 1996, Arnold \& Zink 2011), there are reports of daytime collisions, since many species may collide with reflective buildings when they come down to land for rest or to forage (Klem 1989). Flying in flocks may be another behavioral mechanism that could help avoid daytime collisions, as members divide vigilance making it more likely that the presence of an obstacle will be noticed (Kahle et al. 2016). Although each population occurs in a different context (Loss et al. 2014), the predisposition for collisions can be understood taxonomically. There are super collider species, i.e. those very prone to collisions, and super avoider species, that can avoid collisions (Pouliot 2008, Arnold \& Zink 2011). Bird morphology was not shown to have any relation with mortality rates in early studies (Klem 1990b). However, there is evidence that hummingbirds and swifts are prone to high fatality rates due to the fragility of these small birds, which usually collide at high speeds (Kahle et al. 2016).

Some species are more likely to collide because of their behavioral patterns (Klem 1989, Pouliot 2008). The first paper on collisions found no predisposition to collisions regarding the sex of the individuals involved (Klem 1989). However, further studies have shown a higher propensity for males, which constitute $66 \%$ of all collisions (Pouliot 2008, Kahle et al. 2016). This greater vulnerability may be related to behavioral patterns since males are more aggressive and active in defending their territories (Hager \& Craig 2014). Higher levels of activity, especially during reproductive periods, lead to aggressive behavior among males and, consequently, more collisions with glass panes. In the case of the New Zealand Pigeon Hemiphaga novaeseelandiae, an endemic and near threatened species, the courtship behavior of the males, which exhibit complex flights to impress females, was also related to their more frequent involvement in collisions (not only with glass panes) (Cousins et al. 2012).

There is still no consensus as to whether there is any difference between the mortality 
rates of juveniles (less than one-year-old) versus adult birds (more than one year). Some studies have shown a similar risk of collision for both adults and juveniles (Klem 1989, Sabo et al. 2016), while others have found a higher collision frequency in juveniles compared to adults. This could be explained by the inexperience of juveniles; in another case, two distinct patterns were found: adults of low abundance species and juveniles of high abundance species both had higher mortality rates (Kahle et al. 2016). The explanation for juveniles could be that they are inexperienced fliers and, for adults, territorial defense behavior (Hager \& Craig 2014).

Few studies addressed the behavior of birds towards new objects and whether they learn to avoid them, within the scope of this topic. It is recognized that birds increase their exploitation behavior when they find novelties in their territories and, until they become familiar with them, this greater activity near glass panels can increase the risk of collision (Habberfield \& Clair 2016). Resident species may suffer fewer collisions, due to possible habituation to the presence of glass panes (Parkins et al. 2015), although there is no evidence that birds actually learn to avoid these obstacles (Sabo et al. 2016).

Foraging behavior may also affect collisions rates, mainly when food is near glass panes. Understory and ground species are thus more likely to be involved in collisions since they usually are more common in urban settlements (Cusa et al. 2015, Ocampo-Peñuela et al. 2016), while canopy species tend to maintain safer distances (Sabo et al. 2016). Birds of prey may collide when pursuing their prey (Glue 1971, Newton et al. 1999). In fact, fugue-chase behavior, including predator-prey and male disputes are known to be the cause of a large number of collisions as there is an inherent neglect of birds in relation to the environment during such events (Dunn 1993). For this reason, the Common Kestrel (Falco tinnunculus), which primarily consumes mammals, has a lower collision rate than the Eurasian Sparrowhawk (Accipiter nisus), which mainly feeds on small birds (Newton et al. 1999). In one very peculiar case regarding Cedar Waxwings (Bombycilla cedrorum), they became particularly vulnerable to collisions due to the ingestion of fermented fruits (Ocampo-Peñuela et al. 2016) that caused intoxication and disorientation during flight (Fitzgerald et al. 1990). Although owls do not suffer frequent collisions, it is known that foraging close to windows with lit backgrounds, streets and urban courtyards make them more vulnerable (Hager 2009). Hummingbirds also have a noteworthy high collisions frequency, due to their tendency to fly at high speeds over long distances in search of nectar, characterizing a traplining behavior (Graham 1997, Kahle et al. 2016).

\section{Weather and seasonality}

Collisions occur throughout the year (Klem 1989, Bayne et al. 2012, Ocampo-Peñuela et al. 2016). However, certain seasons have higher collisions rates for different reasons, including changes in bird behavior and plant communities. Most studies found higher collision rates during spring, autumn and summer in the northern hemisphere (Borden et al. 2010, Cousins et al. 2012, Kahle et al. 2016, Ocampo-Peñuela et al. 2016). The plausible explanations for these are: (1) migration and reproduction (Borden et al. 2010), (2) presence of inexperienced juveniles (Kahle et al. 2016), (3) increase in bird abundance (Hager et al. 2008) and (4) territorial defense behavior by adult males (Hager \& Craig 2014). In the winter, the absence of green vegetation in many places also means that there are no reflections against glass panes (Hager et al. 2012, Bayne et al. 2012, Kummer et al. 2016b). However, these patterns probably do not apply to most of Latin America, 
due to the different climatic conditions and seasonality. In a migration passage in Colombia, a peak in collisions was detected during spring (October and November) (Agudelo-Álvarez et al. 2010). However, no differences between seasons were found in collision rates in Brazil (Brisque et al. 2017, Santos et al. 2017).

In terms collisions rates related to the time of day, the results are almost unanimous (Klem 1989, Borden et al. 2010). The highest numbers of deaths were consistently recorded during the morning in various studies, although the collision frequency varied between sites (Hager \& Craig 2014, Parkins et al. 2015, Kahle et al. 2016). However, few studies tested the effects of weather conditions on the collision rate (e.g. Ocampo-Peñuela et al. 2016). They occur both under favorable weather conditions (e.g. sunny days) and those that alter visibility, such as blizzards (Klem 1989).

\section{Surroundings}

The environmental characteristics and anthropogenic influences also widely vary (e.g. Klem 1990b, Rössler et al. 2015) and the solutions may not always be applicable (Brisque et al. 2017). Environmental factors and their attractiveness to birds can influence bird abundance, thus increasing their vulnerability to collisions (Hager et al. 2008, 2013, Cusa et al. 2015). Indeed, a positive correlation between the number of collisions and the distance from urban centers has been reported (Bracey et al. 2016). Birds in more paved and urbanized environments are typical of open areas; while suburban birds are more linked to forest environments (Cusa et al. 2015). However, greater bird diversity usually is found in more natural areas (Hager et al. 2013). Therefore, buildings in rural surroundings are more likely to cause collisions than those in urban centers. In regions with pronounced seasonality (e.g. Canada), rural houses in the fall may have a risk of collision ten times greater than urban houses in winter (Kummer et al. 2016b). However, no differences were found in mortality rates between urban and non-urban predators (Hager 2009) because not all species respond equally to urbanization (Cusa et al. 2015).

The proximity of green areas to glass panes may cause high collision rates, and buildings with nearby green areas are a threat to migratory birds, even in urban centers (Borden et al. 2010), as they can act as "ecological traps", i.e., islands of vegetation that attract birds as a possible resting place but that are set amidst glass-clad buildings. Thus, it is important to have safe fragments in urban areas, allowing resting without great risk of collision (Borden et al. 2010). The effect of distance from vegetation to glass panes also seems to vary over a year (Pouliot 2008, Hager et al. 2013).

Bird feeders, when close to glass windows, may also increase the number of collisions (Klem 1990b). Feeding flocks of small birds can attract predators, such as hawks which, when attempting to capture prey, increase the likelihood of a collision for both predator and prey (Boal \& Mannan 1999). Nevertheless, even when the collision rate is doubled by the presence of feeders (Kummer \& Bayne 2015), the influence of the surrounding habitats still tends to be more important (Kummer et al. 2016a).

\section{Types of construction}

Different types of constructions have different associated collision risks, due to several reasons. Earlier studies found that collisions were more common when large glass panes (i.e., more than 2s.q.) were involved (Klem 1989), and a positive relationship between the amount of glass/nearby environmental resources with collisions has been recognized (Hager et al. 2008, 2013, Cusa et al. 2015, Parkins et al. 2015, 
Ocampo-Peñuela et al. 2016). In one example, only two buildings were responsible for almost half the collisions of the threated Fairy Pitta, Pitta nympha in Asia (Kim et al. 2013).

Glass need not be associated with buildings to cause bird deaths (Klem 1989, Barton et al. 2017, Mitrus \& Zbyryt 2018), but when it is, the percentage area of glass in relation to the facade area is more important than the size of the building itself (Cusa et al. 2015). Large glass areas, when divided into smaller panels, are also less dangerous and have lower collision rates (Kahle et al. 2016).

Glass panes that reflect surrounding vegetation have three times more risk than those that do not (Kummer et al. 2016b), including translucent panes (Agudelo-Álvarez al. 2010). The chance of collisions is also greater if the glass material reflects the image of the habitat (as a mirror), or its internal environment is darker than the external environment (Klem \& Saenger 2013, Klem 2015). However, it is not clear how artificial internal lights influence collisions, as most occur during daylight hours (Parkins et al. 2015). Collisions are also more frequent above three meters and at ground level (Klem 1989). The angle of glass windows can also be important; when the panels are facing the ground, the reflections of the sky and the vegetation are reduced, and so is the collision rate (Klem et al. 2004).

The influence of the age of constructions has been evaluated in a couple of studies. Although birds may become habituated to the places where they have lived for decades, installing glass windows may induce an increase in the collision rate (Klem 1989). Older neighborhoods tend to be more wooded, resulting in a greater number of birds, and thus leading to more collisions (Bayne et al. 2012). Therefore, regardless of the age of the structures, the features that make the area more attractive to birds are more important in an analysis of the possible causes of the collisions.

\section{Future Directions}

Several factors may significantly affect birdwindow collision rates and each case should be considered separately, whether due to differences in bird fauna composition, landscape context, and the architecture of the buildings. In neotropical cities, reflective glass windows have been eventually considered a threat to urban birds (e.g. Agudelo-Álvarez et al. 2010, SantiagoAlarcon et al. 2017). Literature both in Portuguese and in Spanish (e.g., dissertations, theses, local journals, newspapers, and websites) have reported this problem and discussed possible solutions, but often few data are available. Some sites propose - and even sell - possible solutions for mitigation, but without scientific basis.

Glass panes are widely used, even in "green building" projects, where risks of collisions are not considered. The efforts to mitigate bird collisions must be global (Bayne et al. 2012, Winton et al. 2018), but the greatest challenges to solving - or even mitigating - this problem are the lack of information, and - frequently - the extrapolation of findings described for temperate regions to other areas. The species involved and their population dynamics, interspecific interactions, vegetation type(s), climate, urbanization and civil construction are often different, therefore, we barely understand how this problem may affect most of the world's bird species.

Global bird collisions with glass panes are far from being solved. Several studies have tested and proposed mitigating measures (e.g. Loss et al. 2015, Rössler et al. 2015, Kummer et al. 2016a), but they were mostly developed in Northern Hemisphere. Some regions - or countries - have come a long way, both in convincing civilians on 
this severe environmental issue, and in adopting public policies that consider the design of birdfriendly buildings. But they are exceptions in the northern hemisphere as well.

With this review, we showed gaps in the knowledge, and hopefully stimulate further research in tropical regions. For future studies, we propose the following research, mainly in the Southern Hemisphere:

(a) increase the geographic coverage of the studies;

(b) produce more data of greater scope and of long duration, including citizen science;

(c) increase research on susceptibility to collisions, i.e., relating data on morphology, behavior, migratory status, sex, and age, with collision rates;

(d) relate patterns of collisions with seasonality, considering the austral climate;

(e) Produce scientific dissemination texts to encourage the inclusion of citizens and decision makers.

\section{Acknowledgments}

We thank Alexander Christianini and Maurício Cetra for suggestions on earlier version of this manuscript, and two anonymous reviewers for their valuable criticism and suggestions. We also thank Jeremy K. Dickens for English text revision. DJM was supported with grant from Conselho Nacional de Desenvolvimento Científico e Tecnológico (CNPq - 142103/2015-2). The experiments comply with the current laws of Brazil.

\section{REFERENCES}

AGUDELO-ÁLVAREZ L, MORENO-VELASQUEZ I \& OCAMPOPEÑUELA N. 2010. Colisiones de aves contra ventanales en un campus universitario de Bogotá, Colombia. Ornito Colom 10: 3-10.

ARNOLD TW \& ZINK RM. 2011. Collision mortality has no discernible effect on population trends of North American birds. PLoS ONE 6(9): e24708.
BARTON CM, RIDING CS \& LOSS SR. 2017. Magnitude and correlates of bird collisions at glass bus shelters in an urban landscape. PLoS ONE 12(6): e0178667.

BAYNE EM, SCOBIE CAS \& RAWSON-CLARK M. 2012. Factors influencing the annual risk of bird-window collisions at residential structures in Alberta, Canada. Wildl Res 39(7): 583-592.

BOAL CW \& MANNAN RW. 1999. Comparative breeding ecology of Cooper's hawks in urban and exurban areas of southeastern Arizona. J Wildl Manag 63(1): 77-84.

BORDEN WC, LOCKHART OM, JONES AW \& LYONS MS. 2010. Seasonal, taxonomic, and local habitat components of bird-window collisions on an urban university campus in Cleveland, OH. Ohio J Sci 110(3): 44-52.

BRACEY AM, ETTERSON MA, NIEMI G] \& GREEN RF. 2016. Variation in bird-window collision mortality and scavenging rates within an urban landscape. Wilson J Ornithol 128(2): 355-367.

BRISQUE T, CAMPOS-SILVA LA \& PIRATELLI AJ. 2017. Relationship between bird-of-prey decals and bird-window collisions on a Brazilian university campus. Zoologia 34: e13729.

COUSINS RA, BATTLEY PF, GARTRELL BD \& POWLESLAND RG. 2012. Impact injuries and probability of survival in a large semiurban endemic pigeon in New Zealand, Hemiphaga novaeseelandiae. J Wildl Dis 48(3): 567-574.

CUSA M, JACKSON DA \& MESURE M. 2015. Window collisions by migratory bird species: urban geographical patterns and habitat associations. Urban Ecosyst 18(4): 1427-1446.

DUNN EH. 1993. Bird mortality from striking residential windows in winter. J Field Ornithol 64(3): 302-309.

ERICKSON WP, JOHNSON GD \& YOUNG JR DP. 2005. A summary and comparison of bird mortality from anthropogenic causes with an emphasis on collisions. USDA Forest Service Gen Tech Rep PSW-GTR 191: 1029-1042.

FITZGERALD SD, SULLIVAN JM \& EVERSON RJ. 1990. Suspected ethanol toxicosis in two wild cedar waxwings. Avian Dis 34(2): 488-490.

FOLEY JA ET AL. 2005. Global consequences of land use. Science 309: 570-574.

GELB Y \& DELACRETAZ N. 2009. Windows and vegetation: primary factors in Manhattan bird collisions. Northeast Nat 16(3): 455-470.

GLUE DE. 1971. Ringing recovery circumstances of small birds of prey. Bird Study 18(3): 137-146. 
GRAHAM DL. 1997. Spider webs and windows as potentially important sources of hummingbird mortality. J Field Ornithol 68(1): 98-101.

HABBERFIELD MW \& CLAIR CCS. 2016. Ultraviolet lights do not deter songbirds at feeders. J Ornithol 157: 239-248.

HAGER SB. 2009. Human-related threats to urban raptors. J Raptor Res 43: 210-226.

HAGER SB \& CRAIG ME. 2014. Bird-window collisions in the summer breeding season. Peerf 2: e460.

HAGER SB, COSENTINO BJ \& MCKAY KJ. 2012. Scavenging affects persistence of avian carcasses resulting from window collisions in an urban landscape. J Field Ornithol 83(2): 203-211.

HAGER SB, COSENTINO BJ, MCKAY KJ, MONSON C, ZUURDEEG W \& BLEVINS B. 2013. Window area and development drive spatial variation in bird-window collisions in an urban landscape. PLoS ONE 8(1): e53371.

HAGER SB, TRUDELL H, MCKAY KJ, CRANDALL SM \& MAYER L. 2008. Bird density and mortality at windows. Wilson J Ornithol 120(3): 550-564.

KAHLE LQ, FLANNERY ME \& DUMBACHER JP. 2016. Bird-window collisions at a west-coast urban park museum: analyses of bird biology and window attributes from Golden Gate Park, San Francisco. PLoS ONE 11(1): e0144600.

KIM EM, CHOI CY \& KANG CW. 2013. Causes of injury and mortality of Fairy Pitta Pitta nympha on Jeju Island, Republic of Korea. Forktail 29: 145-148.

KLEM JR D. 1989. Bird-window collisions. Wilson Bull 101(4): 606-620.

KLEM JR D. 1990a. Bird Injuries, cause of death, and recuperation from collisions with windows. J Field Ornithol 61: 115-119.

KLEM JR D. 1990b. Collisions between birds and windows: mortality and prevention. J Field Ornithol 61(1): 120-128.

KLEM JR D. 2006. Glass: a deadly conservation issue for birds. Bird Observer 34(2): 73-81.

KLEM JR D. 2009a. Avian mortality at windows: the second largest human source of bird mortality on Earth. Proceedings of the Fourth International Partners in Flight Conference: Tundra to Tropics, p. 244-251.

KLEM JR D. 2009b. Preventing bird-window collisions. Wilson J Ornithol 121: 314-321.

KLEM JR D. 2015. Bird-window collisions: a critical animal welfare and conservation issue. J Appl Anim Welf Sci 18: S11-S17.
KLEM JR D, KECK DC, MARTY KL, BALL AJM, NICIU EE \& PLATT CT. 2004. Effects of window angling, feeder placement, and scavengers on avian mortality at plate glass. Wilson Bull 116(1): 69-73.

KLEM JR D \& SAENGER PG. 2013. Evaluating the effectiveness of select visual signals to prevent bird-window collisions. Wilson J Ornithol 125(2): 406-411.

KUMMER JA \& BAYNE EM. 2015. Bird feeders and their effects on bird-window collisions at residential houses. Avian Conserv Ecol 10(2): 6.

KUMMER JA, BAYNE EM \& MACHTANS CS. 2016a. Comparing the results of recall surveys and standardized searches in understanding bird-window collisions at houses. Avian Conserv Ecol 11(1): 4.

KUMMER JA, BAYNE EM \& MACHTANS CS. 2016b. Use of citizen science to identify factors affecting bird-window collision risk at houses. Condor 118(3): 624-639.

KUMMER JA, NORDELL CJ, BERRY TM, COLLINS VC, TSE CLR \& BAYNE EM. 2016c. Use of bird carcass removals by urban scavengers to adjust bird-window collision estimates. Avian Conserv Ecol 11(2): 12.

LOSS SR, WILL T, LOSS SS \& MARRA PP. 2014. Bird-building collisions in the United States: Estimates of annual mortality and species vulnerability. Condor 116: 8-23.

MACHTANS CS, WEDELES CHR \& BAYNE EM. 2013. A first estimate for Canada of the number of birds killed by colliding with building windows. Avian Conserv Ecol 8(2): 6.

MCDONALD RI. 2008. Global urbanization: can ecologists identify a sustainable way forward? Front Ecol Environ 6(2): 99-104.

MITRUS C \& ZBYRYT A. 2018. Reducing avian mortality from noise barrier collisions along an urban roadway. Urban Ecosyst 21: 351-356.

MYERS N, MITTERMEIER RA, MITTERMEIER CG, DA FONSECA GAB \& KENT J. 2000. Biodiversity hotspots for conservation priorities. Nature 403: 853-858.

NEWTON I, WYLLIE I \& DALE L. 1999. Trends in the numbers and mortality patterns of Sparrowhawks (Accipiter nisus) and Kestrels (Falco tinnunculus) in Britain, as revealed by carcass analyses. J Zool 248(2): 139-147.

OCAMPO-PEÑUELA N, WINTON RS, WU CJ, ZAMBELLO E, WITTIG TW \& CAGLE NL. 2016. Patterns of bird-window collisions inform mitigation on a university campus. PeerJ 4: e1652.

OGDEN LJE. 1996. Collision course: the hazards of lighted structures and windows to migrating birds. Fatal Light Awareness Program (FLAP). paper 3. Available at: http:// 
digitalcommons.unl.edu/flap/3. Accessed on 20 July 2018.

PARKINS KL, ELBIN SB \& BARNES E. 2015. Light, glass, and bird-building collisions in an urban park. Northeast Nat 22(1): 84-94.

POULIOT Y. 2008. Les collisions d'oiseaux à l'édifice Marly à Sainte-Foy, Québec, de 1978 a 2007. Can Field Nat 122(2): 153-157.

RIBEIRO BC \& PIRATELLI AJ. IN PRESS. Circular-shaped decals prevent bird-window collisions. Rev Bras Ornitol.

RÖSSLER M, NEMETH E \& BRUCKNER A. 2015. Glass pane markings to prevent bird-window collisions: less can be more. Biologia 70(4): 535-541.

SABO AM. HAGEMEYER NDG, LAHEY AS \& WALTERS EL. 2016. Local avian density influences risk of mortality from window strikes PeerJ 4: e2170.

SANTIAGO-ALARCON D \& DELGADO-V CA. 2017. Warning! Urban threats for birds in Latin America. In: MacGregor-Fors I \& Escobar-Ibáñéz JF (Eds), Avian ecology in Latin American cityscapes. Springer, p. 125-142.

SANTOS LPS, ABREU VF \& VASCONCELOS MF. 2017. Bird mortality due to collisions in glass panes on an Important Bird Area of southeastern Brazil. Rev Bras Ornitol 25(2): 90-101.

SEEWAGEN CL \& SHEPPARD C. 2017. Bird collisions with glass: an annotated bibliography. American Bird Conservancy, Washington, $41 \mathrm{p}$.

WINTON RS, OCAMPO-PEÑUELA N \& CAGLE N. 2018. Georeferencing bird-window collisions for targeted mitigation. PeerJ 6: e4215.

\section{SUPPLEMENTARY MATERIAL}

\section{Table SI. Bird species cited as colliders with glass panes in 53 sampled papers.}

\section{How to cite}

BASILIO LG, MORENO DJ \& PIRATELLI AJ. 2020. Main causes of birdwindow collisions: a review. An Acad Bras Cienc 92: e20180745. DOI 10.1590/0001-3765202020180745.

Manuscript received on July 20, 2018; accepted for publication on January 10, 2019

\section{LAY G. BASILIO 1}

https://orcid.org/0000-0002-7402-5425

\section{DANIELE J. MORENO ${ }^{2}$}

http://orcid.org/0000-0001-9394-3478

\section{AUGUSTO J. PIRATELLI ${ }^{3}$}

https://orcid.org/0000-0002-1538-791X

${ }^{1}$ Laboratório de Ecologia e Conservação, Universidade Federal de São Carlos, Rodovia João Leme dos Santos, Km 110, Itinga, 18052-780 Sorocaba, SP, Brazil

${ }^{2}$ Programa de Pós-Graduação em Ecologia e Recursos Naturais, Universidade Federal de São Carlos, Rodovia Washington Luiz, Km 235, 13565-905 São Carlos, SP, Brazil

${ }^{3}$ Departamento de Ciências Ambientais, Centro de Ciências e Tecnologia para a Sustentabilidade/CCTS, Universidade Federal de São Carlos, Rodovia João Leme dos Santos, Km 110, Itinga, 18052-780 Sorocaba, SP, Brazil

\section{Correspondence to: Augusto João Piratelli}

E-mail:piratelli@ufscar.br

\section{Author contributions}

LGB and AJP conceived the idea designed the studies; LGB, DJM and AJP collected and analyzed data; all the authors wrote the manuscript and approved the final version.

\section{(cc) BY}

